BN $(5,9 \%)$, Xấu 0 BN.

- 32/34 BN (94,1\%) liền xương các ổ gãy, khớp chày sên về đúng vị trí giải phẫu, không doãng mộng chày mác. Có 2 BN $(5,9 \%)$ thoái hóa khớp chày sên.

- Gãy mắt cá sau di lệch nên được nắn chỉnh và cố định vững chắc bằng vít xốp hoặc nẹp vít với đường mổ sau ngoài hoặc sau trong. Nên kết xương mác, mắt cá sau (nểu có) rôi đến mắt cá trong. Bắt vít cố định mộng chày mác được chỉ định khi test Cotton $(+)$.

- Điều trị bằng phấu thuật nắn chỉnh mở và kết hợp xương bên trong giúp BN gãy Dupuytren phục hồi được giải phẫu và chức năng cổ chân, đặc biệt khi kèm gãy mắt cá sau.

\section{TÀl LIẸU THAM KHẢO}

1. Burwell H.N. và Charnley A.D. (1965). The treatment of displaced fractures at the ankle by rigid internal fixation and early joint movement. J Bone Joint Surg Br, 47(4), 634-660.
2. Verhage S. (2019), Management of the posterior malleolus in trimalleolar fractures. 179, Leiden University, the Netherlands.

3. Karande V., Nikumbha V.P., Desai A. el all. (2017), "Study of surgical management of malleolar fractures of ankle in adults", Int J Orthop Sci, 3(3), 783-787.

4. Bartoníček J., Rammelt S., Tuček M. el all. (2015), "Posterior malleolar fractures of the ankle", Eur J Trauma Emerg Surg, 41(6), 587-600.

5. Ma Ngọc Thành (2010), Đánh giá kết quả phẫu thuâtt gã̃y kín mắt cá chân tại bệnh viện hữu nghị Việt Đức, Luận văn thạc sĩ y học đaji học y Hà Nội.

6. Đồ Tuấn Anh (2016). Kết quả phầu thuật gãy kín xương mắt cá chân ở người trướng thành tại bênh viện Hữu nghị Việt Đức. Luận văn thạc sĩ y học đại hợc y Hà Nối.

7. Tosun B., Selek O., Gok U. et all. (2018) "Posterior Malleolus Fractures in Trimalleolar Ankle Fractures: Malleolus versus Transyndesmal Fixation". Indian J Orthop, 52(3), 309-314.

8. Mak M.F., Stern R., Assal M.' (2018). "Repair of syndesmosis injury in ankle fractures". EFORT Open Rev, 3(1), 24-29.

\title{
ĐÁNH GIÁ THỰC TRANG TỔN THƯƠNG THÂN CẤP THEO THANG ĐIỂM RIFLE Ở BÊNHH NHÂN ĐIỀU TRI TẠI KHOA HỒI SỨC TÍCH CỰC VÀ CHỐNG ĐộC
}

\section{TÓM TẮT ${ }^{3}$}

Mục tiêu: Phân tích đặc điểm, các yếu tỗ nguy cơ và tiên lượng tử vong của bệnh nhân tôn thương thận cấp. Đối tượng và phương pháp: 201 bệnh nhẩn điều trị tại khoa Hồi sức tích cực và Chống độc từ tháng 03 đến tháng 09 năm 2020. Tiến cứu mô tả. Kết quả: Tuổi TB 80.1; $84.1 \%$ là nam, ngày điều trị ICU TB 14.6, tỉ lệ TV gấp 3.6 lần ở nhóm AKI so với NAKI.Tỷ lệ AKI 34.3\%; mắc mới $19.4 \%$; hồi phục $31.9 \%$; tử vong: $40.6 \%$. Nguyên nhân: sốc nhiếm khuẩn $(52.2 \%)$, thiếu dịch $(14.5 \%)$, suy tim $(13 \%)$, thuốc độc với thận $(8.7 \%)$. Các yếu tố nguy cơ AKI: suy đa tạng (OR 6.8), sốc (OR 4.6), nhiễm khuẩn nặng (OR 3.2). Nguy cơ tử vong: sốc (OR 13.0), suy đa tang (OR 11.3), phải thở máy (OR 8.4), suy gan, rối loạn đông máu (OR 4.4). AKI thời điểm nặng nhất liên quan đển tỷ lề tử vong: R (OR 2.3), I (OR 3.7), $\mathrm{F}(\mathrm{OR}$ 4.5). Sốc nhiễm khuân làm tăng tử vong ở bệnh nhân AKI lên 3.5 lần $(p<0.05)$, suy tim là 2.6 lần $(p<0.05)$ và dùng thuốc độc với thận là 1.5 lần $(p<0.05)$ so với nhóm NAKI. Kết luận: Phân độ RIFLE

*Bênh viên Hữu Nghi

Chịu trách nhiệm chính: Tô Hoàng Dương

Email: dr.hoangduong@gmail.com

Ngày nhận bài: 22/8/2021

Ngày phản biên khoa hoc: 17/9/2021

Ngày duyệt bài: 2/10/2021

\section{Nguyễn Thế Anh*, Tô Hoàng Dương*}

đơn giản, áp dụng tốt tại các đơn vị hồi sức để đánh giá mức độ, tiến triển của tổn thương thận cấp.

Tư khóa: Đặc điểm, yếu tố nguy cớ, tiên lượng tử vong, tổn thương thận cấp.

\section{SUMMARY \\ ASSESSMENT OF THE CURRENT SITUATION OF ACUTE KIDNEY INJURY BY RIFLE SCOPE INPATIENTS TREATED AT CRITICAL CARE AND POISONING CONTROL DEPARTMENT}

Objectives: To analyze the characteristics, risk factors and mortality prognosis of patients with acute kidney injury. Subjects and method: 201 patients treated at the critical care and poisoning control department from March to September 2020. Descriptive prospective. Results: Average age 80.1; $84.1 \%$ were male, the ICU treatment day was 14.6 , the rate of mortality was 3.6 times higher in the AKI group than in the NAKI group. The rate of AKI was $34.3 \%$; $19.4 \%$ new cases; recovered $31.9 \%$; mortality: $40.6 \%$. Causes: septic shock (52.2\%), fluid deficiency $(14.5 \%)$, heart failure $(13 \%)$, nephrotoxic drugs $(8.7 \%)$. Risk factors for AKI: multiple organ failure (OR 6.8), shock (OR 4.6), severe infection (OR 3.2). Risk of death: shock (OR 13.0), multiple organ failure (OR 11.3), mechanical ventilation (OR 8.4), liver failure, coagulopathy (OR 4.4). The most severe AKI was associated with mortality: R (OR 2.3), I (OR 
3.7), F (OR 4.5). Septic shock increased mortality in patients with AKI by 3.5 times $(p<0.05)$, heart failure by 2.6 times $(p<0.05)$ and nephrotoxic drugs by 1.5 times $(p<0.05)$ compared with NAKI group. Conclusion: The RIFLE classification is simple, well applied in intensive care units to assess the extent and progression of acute kidney injury.

Keywords: Characteristics, risk factors, mortality prognosis, acute kidney injury.

\section{I. ĐĂT VẤN ĐỀ}

Tổn thương thân cấp (AKI) là một hội chứng thường gặp trên bệnh nhân hồi sức cấp cứu với tỉ lệ tử vong cao. Tỉ lệ xuất hiện AKI ở bệnh nhân Hồi sức cấp cứu từ 4 - 25\%. Tỉ lệ tử vong của AKI ở bệnh nhân hồi sức từ $19-83 \%$, ở bệnh nhân cần lọc máu hoặc kết hợp với suy đa tạng tử vong lên tới 50-90\% [1], [2], [3]. Ở bệnh nhân điều trị tại khoa Hồi sức tích cực, AKI thường xảy ra với nhiều nguyên nhân: thiếu dịch, sốc nhiễm khuẩn, suy đa tạng, sốc chấn thương, sử dụng thuốc độc với thận... Trong thực tế lâm sàng, người bệnh có thể có nhiều nguy cơ và nguyên nhân AKI cùng lúc.

Phân độ RIFLE (Tác giả Bellomo và cs - năm 2004) đã được nhiều tác giả trên thế giới cũng như tại Việt Nam áp dụng đánh giá AKI trên bệnh nhân Hồi sức [4]. Phân độ này giúp người thầy thuốc chẩn đoán $\mathrm{AKI}$ theo từng giai đoạn nguy cơ tới giai đoạn tổn thương hoặc suy từ đó đưa ra các can thiệp điều trị phù hợp, giúp cải thiện tiên lượng của các bệnh nhẩn AKI. Tại khoa Hồi sức tích cực và Chống độc - Bệnh viện Hữu Nghị Việt Xô, AKI là một vấn đề cần thiết nhưng chưa được nghiên cứu đầy đủ. Chính vì vậy, chúng tôi đã tiến hành nghiên cứu đề tài:
"Đánh giá thực trạng tổn thương thận cấp theo thang điểm RIFLE ở bệnh nhân điều trị tại Khoa Hồi sức tích cực và chống độc"với 02 mục tiêu:

1. Phân tích đặc điểm bệnh nhân và biến cố tôn thương thận cấp ở bệnh nhân tại Khoa Hồi sức tích cực-chống độc

2. Đánh giá các yếu tố nguy cơ và tiên lượng tử vong ở bệnh nhân tổn thương thận cấp tại Khoa hồi sức tích cực - chống độc

\section{II. ĐỐI TƯợNG VÀ PHƯƠNG PHÁP NGHIÊN CỨU}

1. Đối tượng nghiên cứu: 201 bệnh nhân điều trị HSTC\&CĐ - BV Hữu Nghị Việt Xồ.

Tiêu chuẩn lựa chọn: Các $B N$ điêu trị tại khoa Hồi sức tích cực và Chống độc - Bệnh viện Hữu Nghị Việt Xô từ tháng 03 đến tháng 09 năm 2020

Tiêu chuẩn loại trừ:

- BN có tiền sử suy thận mạn

- BN điều trị tại khoa Hồi sức tích cực dưới 02 ngày, không đủ số liệu nghiên cứu

- $B N$ và người nhà không đồng ý tham gia nghiên cứu

2. Thời gian nghiên cứu: Từ $3 / 2020$ đến 09/2020

3. Phương pháp nghiên cứu: Tiến cứu, mô tả.

4. Xử lý số liệu: Bằng phần mềm SPSS 16.0

\section{KẾT QUẢ NGHIÊN CỨU}

Chúng tôi đã tiến hành nghiên cứu trên 201 bênh nhân vào điều trị tai khoa HSTC\&CĐ từ 3/2020 đến 9/2020 với những đặc điểm như sau:

\section{1. Đặc điểm điểm chung của nhóm} nghiên cứu:

- Phân bố bệnh nhân theo tuổi

\begin{tabular}{|c|c|c|c|c|}
\hline & Chung & NAKIN** & AKIN* & $\mathbf{P}$ \\
\hline $\begin{array}{c}\text { Tuối trung bình (năm) } \\
X \pm S D \text { (min-max) }\end{array}$ & $\begin{array}{l}78.5 \pm 10.6 \\
(47-102)\end{array}$ & $\begin{array}{l}76.8 \pm 7.6 \\
(47-94)\end{array}$ & $\begin{array}{l}80.1 \pm 5.6 \\
(78-102)\end{array}$ & $>0.05$ \\
\hline $\begin{array}{c}\text { Số ngày đîều trị (ngày) } \\
X \pm S D \text { (min-max) }\end{array}$ & $\begin{array}{c}13.6 \pm 7.6 \\
(2-48)\end{array}$ & $\begin{array}{c}12.7 \pm 5.7 \\
(2-35)\end{array}$ & $\begin{array}{c}14.6 \pm 4.6 \\
(7-48)\end{array}$ & .05 \\
\hline Tỷ lệ tử vong (\%) & 33.8 & 59.4 & 29.5 & $<0.01$ \\
\hline
\end{tabular}

(*AKI: tốn thương thận cấp, **NAKI: không tổn thương thận cấp)

2. Đặc điểm tổn thương thận cấp

2.1. Ti lệ mắc tổn thương thận câp

Thời điếm

Tỷ lệ (\%)

2.2. Tỷ lệ các mức độ tổn thương thận cấp theo thời gian

\begin{tabular}{|c|c|c|c|c|}
\hline Mức độ & Vào khoa & Nặng nhất & Rời khoa & \multirow{2}{*}{ P } \\
\hline Bình thường $(n, \%)$ & $39(56.5 \%)$ & $0(0.0 \%)$ & $22(31.9 \%)$ & \\
\cline { 1 - 3 }$(n, \%)$ & $12(17.4 \%)$ & $11(15.9 \%)$ & $11(15.9 \%)$ & \multirow{2}{*}{0.05} \\
\hline $\mathrm{I}(\mathrm{n}, \%)$ & $11(15.9 \%)$ & $19(27.5 \%)$ & $9(13.0 \%)$ & \\
\hline $\mathrm{F}(\mathrm{n}, \%)$ & $7(10.2 \%)$ & $37(56.6 \%)$ & $27(39.1 \%)$ & \\
\hline
\end{tabular}


2.3. Tỷ lệ hồi phục của tổn thương thận cấp

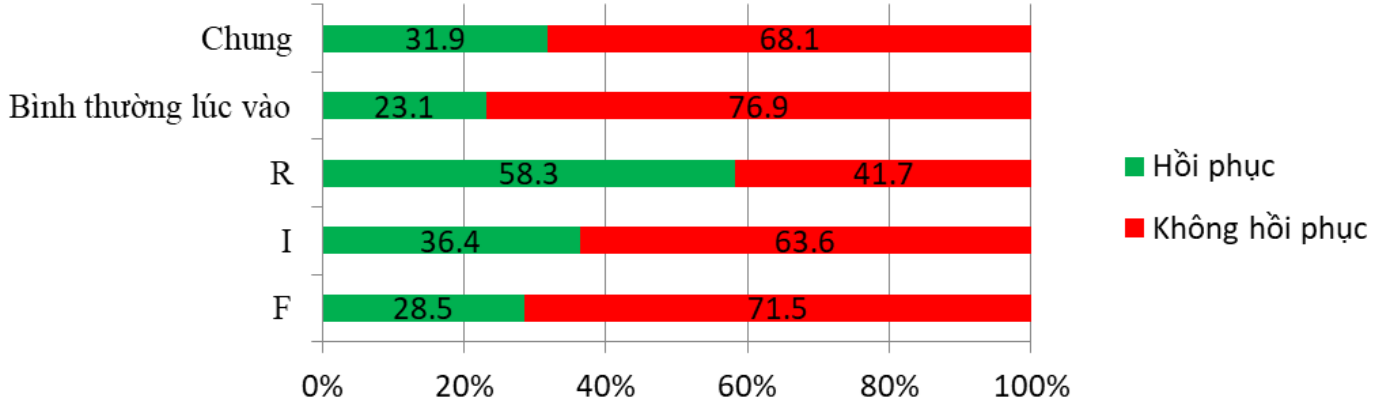

\subsection{Tỷ lệ nguyên nhân và các phương pháp điêu trị suy thận cấp}
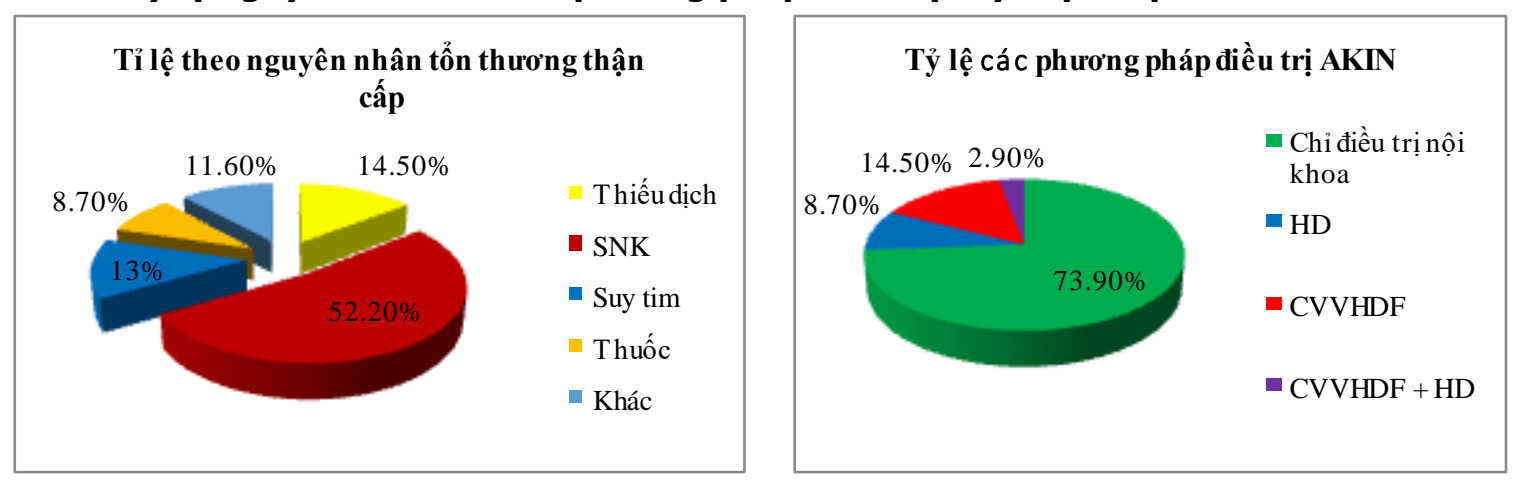

2.5. Tỷ lệ tử vong ở các mức độ suy thận cấp (thời điểm lúc vào khoa)

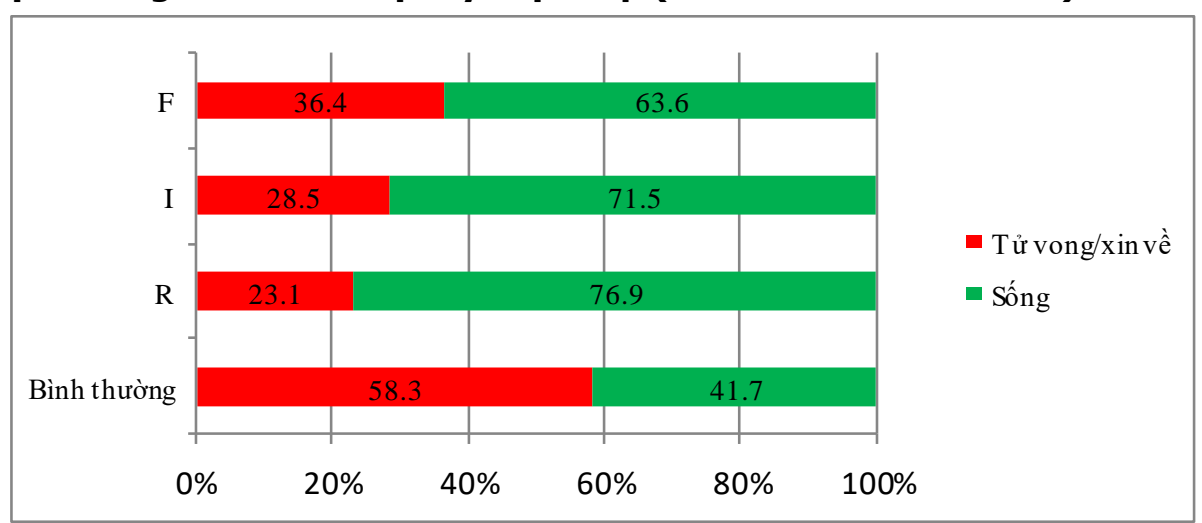

3. Các yếu tố nguy cơ và tiên lượng tử vong ở bệnh nhân AKI

3.1. Liên quan giữa các yêu tố nguy cơ và AKI

\begin{tabular}{|c|c|c|c|}
\hline Thống số & Hệ số beta & OR (95\% CI) & $\mathbf{P}$ \\
\hline Suy đa tạng ( $\geq 2$ tạng) & 1,98 & $6,8(2,93-16,10)$ & $<0.01$ \\
\hline Sốc & 1,67 & $4,6(1,24-7,25)$ & $<0.05$ \\
\hline Nhiêm khuấn nặng & 0,94 & $3.2(2,11-5,90)$ & $<0.05$ \\
\hline Thiếu dịch & 0,85 & $2,8(1,73-7,02)$ & $<0.01$ \\
\hline Suy tim & 0,74 & $2.6(1,43-6,54)$ & $<0.01$ \\
\hline Suy gan, rối loạn đông máu & 0,61 & $2,5(1,10-3,64)$ & $<0.05$ \\
\hline Dùng thuôc độc với thận & 0.51 & $2.1(0.90-3.71)$ & $<0.05$ \\
\hline Thở máy & 0,48 & $1,8(2,07-7,10)$ & $<0.01$ \\
\hline Đái tháo đường/Tăng đường máu & 0,46 & $1.60(0,41-1,20)$ & $<0.05$ \\
\hline Tiêu cơ vần & 0,32 & $1,4(2,56-10,02)$ & $<0.01$ \\
\hline
\end{tabular}


3.2. Liên quan giữa yếu tố nguy cơ và tử vong ở bệnh nhân AKI

\begin{tabular}{|c|c|c|c|}
\hline Thông số & Hệ số beta & OR (95\% CI) & P \\
\hline Sốc & 3,402 & $13.0(3,26-36,40)$ & $<0.001$ \\
\hline Suy đa tạng ( $\geq 2$ tạng) & 3,113 & $11,3(1,01-66,02)$ & $<0.05$ \\
\hline Phải thở máy & 2,529 & $8.4(4,23-86,12)$ & $<0.005$ \\
\hline Suy gan, rối loạn đông máu & 1.684 & $4,4(1,61-12,23)$ & $<0,05$ \\
\hline Nhiêm khuấn nặng & 1.954 & $2,9(0,34-5,18)$ & $<0,05$ \\
\hline Suy tim & 1.512 & $2,7(0.33-3,39)$ & $<0,05$ \\
\hline ĐTĐ/ RL đường máu & 1.203 & $2.1(0.32-3.2)$ & $<0.05$ \\
\hline Dùng thuốc độc với thận & 0.812 & $1.5(0.32-3.2)$ & $<0.05$ \\
\hline
\end{tabular}

3.3. Liên quan giữa mức độ nặng AKI ở thời điếm nặng nhất với tử vong

\begin{tabular}{|c|c|c|c|}
\hline Mức độ & Hệ số beta & OR (95\% CI) & P \\
\hline AKI nặng nhất với NAKI & & & \\
\hline R & 0.61 & $2.3(1.76-3.41)$ & $<0.05$ \\
\hline I & 0.83 & $3.7(3.13-6.12)$ & $<0.05$ \\
\hline F & 1.91 & $4.5(4.11-8.72)$ & $<0.05$ \\
\hline
\end{tabular}

3.4. Liên quan giữa các nhóm bệnh với tử vong

\begin{tabular}{|c|c|c|c|}
\hline 3hóm bệnh & Hệ số beta & OR (95\% CI) & p \\
\hline Sốc nhiêm khuấn & 0.71 & $3.5(2.45-5.74)$ & $<0.05$ \\
\hline Suyy tim & 0.73 & $2.6(2.13-3.80)$ & $<0.05$ \\
\hline Thiếu dịch & -0.02 & $1.03(0.45-.31)$ & $>0.05$ \\
\hline Thuốc độc với thận & 1.01 & $1.51(1.15-2.70)$ & $<0.05$ \\
\hline Khác & 0.31 & $1.71(0.57-3.12)$ & $>0.05$ \\
\hline
\end{tabular}

\section{BÀN LUÂN}

1. Đăc điểm chung. Tuổi trung bình của bệnh nhân tương đối cao (78.5 \pm 10.6 tuổi) và không có sự khác biệt có ý nghĩa thống kê giữa hai nhóm. Kết quả này cao hơn một số nghiên cứu khác: Đặng Thị Xuân (2016) là 55.3 tuổi [5], Lê Diễm Tuyết (2010) là 51.2 tuổi [6], Uchino là 67 tuổi [7]

Bệnh nhân AKI điều trị Hồi sức trung bình $14.6 \pm 4.6$ ngày, dài hơn bênh nhân NAKI là $12.7 \pm$ $5.7(p<0.05)$. Như vậy, AKI cấp là một yếu tố kéo dài thời gian điều trị hồi sức của bệnh nhân.

Tỉ lệ tử vong ở bệnh nhân AKI là $40.6 \%$ cao hơn nhóm NAKI là $29.5 \%$, OR 3.6, p<0.01. Nói cách khác bệnh nhân AKI có nguy cơ tử vong cao gấp 3.6 lần so với bệnh nhân NAKI.Tỉ lệ này tương đương với tác giả Lê Thị Diễm Tuyết là $52,5 \%[6]$.

\section{2.Đặc điểm tổn thương thận cấp}

2.1. Tỉ lệ mắc tổn thương thận câp. Tỉ lệ AKI của mẫu nghiên cứu là $34.3 \%$, trong đó tỷ lể trước lúc vào khoa là $14.9 \%$, mắc mới tại khoa Hồi sức là $19.4 \%$. Kết quả này thấp hơn so với nghiên cứu của Đặng Thị Xuân (2016) (tỉ lệ 45.5\%) [5] nhưng tương tự Uchino $S$. với tỉ lể AKI là $35.7 \%$ [7].

2.2. Tỷ lể các mức độ tổn thương thận cấp theo thời gian. Có 39 (56.5\%) bệnh nhân xuất hiện $A K I$ trong quá trình điều trị tai Khoa Hồi sức. Có 50 (72.5\%) bệnh nhân có tiến triển
AKI cấp tăng lên trong quá trình điều trị. Nhìn chung, mức độ AKI cấp tăng dần trong giai đoạn đầu, sau đó phân bố theo 02 chiều hướng: giảm dần và phục hồi hoặc tăng lên và không hồi phục. Đặng Thị Xuân (2016) chỉ ra tỉ lệ AKI cấp tiến triển khác nhau giữa các mức độ. Với mức độ AKI lúc vào viện: Rvv (26,7\%) - Ivv (24,3\%) - Fvv (30,6\%), sau khi tiến triển, các mức độ suy thận nặng nhất là độ Rmax $(24,7 \%)$ - Imax $(28,6 \%)$ - Fmax (chiếm tỉ lệ cao nhất 46,7\%) [5]. Nghiên cứu của Hoster E. A. (2006) thây AKI cấp chiếm $67,2 \%$ bệnh nhân hồi sức, trong đó $45 \%$ xuất hiện sau vào viện[2].

2.3. Tỷ lế hồi phự của AKI câp. Tỷ lê phục hồi sau AKI cấp chung là $31.9 \%$, trong đó phục hồi nhiều nhất là nhóm $\mathrm{R}(58.3 \%)$, tiếp theo là nhóm I (36.4\%), nhóm $\mathrm{F}(28.5 \%)$, thấp nhất là nhóm bình thường lúc vào khoa (23.1\%). Tác giả Đặng Thị Xuân (2016) thấy có 104 bệnh nhân $(40,8 \%)$ hồi phục chức năng thận, 151 bệnh nhân $(59,2 \%)$ chức năng thận chưa hồi phục khi ra viện hoặc tử vong. Có sự khác nhau về tỉ lệ hồi phục ở các mức độ $A K I$ với $p<0,001$.

2.4. Tý lệ các nguyên nhân và phương pháp điều trị suy thận cấp. Nguyên nhân hàng đầu gây AKI cấp là sốc nhiễm khuẩn $(52.2 \%)$, tiếp đó là thiếu dịch $(14.5 \%)$, suy tim $(13 \%)$, thuốc $(8.7 \%)$, nguyên nhân khác $(11.6 \%)$. Tỷ lệ căn nguyên sốc nhiễm khuẩn chiếm đa số tương đồng với các nghiên cứu của Đặng Thị Xuân (2016) là 43.9\% [5], nghiên cứu 
BEST, các tác giả đã nhận thấy 47,5\% bệnh nhân AKI cấp liên quan với tình trạng sốc nhiễm khuẩn, 34\% liên quan với phẫu thuật lớn, 27\% liên quan với sốc tim, $26 \%$ liên quan với thiếu thể tích và $19 \%$ liên quan với sử dụng thuốc [7].

Có $73.9 \%$ bệnh nhân AKI cấp được điều trị điều trị bằng các phương pháp nội khoa, trong khi $26.1 \%$ bệnh nhân được phối hợp điều trị với các phương pháp lọc máu (14.5\% CVVHDF, $8.7 \% \mathrm{HD}$ và $2.9 \%$ là phổi hợp cả 2 phương pháp lọc). Tỷ lệ bệnh nhân được chỉ định lọc máu của chúng tôi thấp hơn của tác giả Đặng Thị Xuân (2016): $26.1 \%$ so với 34.5\% [5]. Tác giả Abosaif N.Y. (2005) thấy 38,8\% bệnh nhân AKI cần lọc máu, bệnh nhân AKI nặng hơn thì tỉ lệ phải lọc máu cao hơn: $\mathrm{R}(28,3 \%)-\mathrm{I}(50.5 \%)-\mathrm{F}(58 \%)$ [1].

2.5. Tỷ lệ tử vong ở các mức độ suy thận câp (thời đîểm lúc vào khoa). Tỷ lệ tử vong cao nhất ở nhóm bình thường (58.3\%), tiếp sau là nhóm mức độ $\mathrm{F}(36.4 \%)$. Tỷ lệ tử vong thấp nhất ở nhóm mức độ R (23.1\%)

\section{Các yếu tố nguy cơ và tiên lượng tử vong ở bệnh nhân AKI}

3.1. Liên quan giữa các yếu tố nguy co và $\boldsymbol{A K I}$. Suy đa tạng là một bệnh cảnh nặng nề nhất của bệnh nhân hồi sức, dó đó nó cũng là yếu tố làm tăng AKI cấp lên 6.8 lần, tiếp theo đó là tình trạng sốc (nhiểm khuẩn, sốc tim...) với OR là 4.6 và nhiếm khuẩn nặng với $O R$ là 3.2 . Kết quả này tương tự nghiên cứu của Đặng Thị Xuân (suy đa tạng: OR là 7.3, sốc: OR là 2.5, nhiễm khuẩn nặng: OR là 2.1) [5]

Tuy nhiên, ở nghiên cứu của chúng tôi, bệnh nhân gần như toàn bộ là người cao tuổi, nên yếu tố tuổi cao bị "triệt tiêu" và không thây được là yếu tố nguy cơ gây AKI cấp như trong nghiên cứu của Đặng Thị Xuân (tuổi cao có OR là 1.8) [5].

Ngoài ra trong nghiên cứu của chúng tôi còn chỉ ra 02 yếu tố khác có liên quan đến nguy cơ AKI cấp là: dùng thuốc độc với thận (OR là 2.1) và đái tháo đường/rối loạn tăng đường máu (OR là 1.6)

3.2. Liên quan giữa yếu tố nguy cơ và tử vong ở bệhh nhân AKI. Nghiên cứu của chúng tôi đã chỉ ra các yếu tố có liên quan nhất đến tử vong trên bệnh nhân AKI là: sốc (OR 13.0), suy đa tạng (OR 11.3), phải thở máy (OR 8.4). So sánh với kết quả nghiên cứu của Đặng Thị Xuân (2016), kết quả của chúng tôi có những khác biệt nhất định. Về mặt thứ tự $\mathrm{OR}$ cao đến thấp của Đặng Thị Xuân là: phải thở máy (OR 34.1), sốc (OR 11.0), suy đa tạng (OR 8.3) [5]. Về mặt các yếu tố nguy cớ, nghiên cứu của chúng tôi chỉ ra thêm các yếu tố liên quan chặt chẽ đến tử vong của bệnh nhân AKI cấp là nhiễm khuẩn năng ( $O R$ 2.9), suy tim (OR 2.7), đái tháo đường/rối loạn đường máu (OR 2.1), dùng thuốc độc với thận (OR 1.5). Điều này có thể lý giải do đặc thù nhóm bệnh nhân trong nghiên cứu của chúng tôi đa phần mắc nhiều bệnh phối hợp và chức năng thận đã bị suy giảm theo tuổi do đó các biến đổi có thể ảnh hưởng lớn hơn rất nhiều đến tỷ lệ tử vong của bệnh nhân.

Kết quả của nghiên cứu tương tự thực hiện bởi tác giả Uchino Shigehiko và cộng sự (2005) nhận thấy nguy cơ độc lập liên quan tới tử vong bệnh viện của AKI cấp là bệnh nhân phải sử dụng thuốc vận mạch (OR:1,95; 95\% CI: 1,50$2,55 ; \mathrm{p}=0,001)$, phải thở máy ( $O R ; 2,11 ; 95 \%$

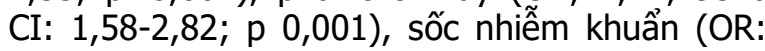
1,36; 95\% CI: 1,03-1,79; $p=0,03$ ), sốc tim (OR: $1,41 ; 95 \%$ CI: $1,05-1,90 ; p=0,02)$, hội chứng gan thận (OR: 1,$87 ; 95 \%$ CI: 1,07-3,28; $\mathrm{p}=0,03$ ), sốc tim (OR: 1,$41 ; 95 \%$ CI: $1,05-1,90$; $\mathrm{p}=0,02)$, hội chứng gan thận (OR: 1,87; $95 \%$ CI: $1,07-3,28 ; p=0,03)$ [7].

3.3. Liên quan giữa mức độ nặng AKI ở thời điểm nặng nhất với tử vong. Về cơ bản, mức độ AKI cấp tại thời điểm nặng nhất có liên quan đến tỷ lệ tử vong, mức độ tổn thương càng nặng thì tỷ lệ tử vong càng cao. Cụ thể, trị số $O R$ (P) tử vong trên nhóm bệnh nhân tổn thương mức độ $R, I, F$ lần lượt là: $2.3(p<0.05), 3.7$ $(p<0.05)$ và $O R \quad 4.5(p<0.05)$. Điêu này cũng phù hợp với diễn biến bệnh của từng bệnh nhân, đó là ở thời điểm bệnh nhân bệnh nặng nhất trong đó có tình trạng AKI cấp, khả năng tiên lượng tử vong sẽ chính xác nhất.

Kết quả của chúng tôi tương tự như kết quả và phân tích của một số tác giả. Tác giả Đặng Thị Xuân (2016) chỉ ra trị số OR tương ứng với các mức độ $R, I, F$ lần lượt là: 1,$9 ; 2,2$ và 5,2 [5]. Theo Hoster E.A, nếu đánh giá theo RIFLEmax thì các mức độ AKI theo phân độ RIFLE đều làm tăng nguy cơ tử vong so với bệnh nhân NAKI: độ I: OR 1,4 (95\% CI:1,02- 1,88; $\mathrm{p}=0,037)$, độ $\mathrm{F}:$ OR 2,7 (95\% CI:2,03 - 3,55; $\mathrm{p}<0,001)[2]$.

3.4. Liên quan giứa các nhóm bênh với tử vong. Bệnh nhân sốc nhiễm khuẩn làm tăng tử vong ở bệnh nhân AKI cấp lên 3.5 lần $(p<0.05)$, suy tim là 2.6 lần $(p<0.05)$ và dùng thuốc độc với thận là 1.5 lần $(p<0.05)$ so với nhóm NAKI. Thiếu dịch và các nguyên nhân khác không liên quan có ý nghĩa với tỷ lệ tử vong.

Kết quả này tương tự với một số nghiên cứu. Tác giả Đặng Thị Xuân đã nhiễm khuẩn làm tăng tử vong ở bệnh nhân nặng có AKI lên 2,1 lần 
(95\% CI: $1,13-3,8 ; p<0,05)$, suy gan - rối loạn đông máu làm tăng 2,8 lần ( $95 \% \mathrm{CI}: 1,15-6,7$; $\mathrm{p}<0,001)$. Nhóm bệnh tim mạch và viêm tụy cấp không rõ mối liên quan với tỷ lệ tử vong [5]. Phân tích của Schrier Robert W chỉ ra tỷ lệ AKI cấp ở bệnh nhân nhiễm khuẩn tử vong lển tới $70 \%$ so với AKI cấp đơn thuân là $45 \%$.

\section{KẾT LUÂ̂N}

Phân độ RIFLE đơn giản, áp dụng tốt tai các đơn vị hồi sức để đánh giá mức độ, tiến triển của AKI

\section{TÀI LIÊU THAM KHẢO}

1. Abosaif N. Y., Tolba Y. A., et al. (2005), "The outcome of acute renal failure in the intensive care unit according to RIFLE: model application, sensitivity, and predictability", Am J Kidney Dis, 46(6), pp. 1038-48.

2. Hoste E. A., Clermont G., et al. (2006), "RIFLE criteria for acute kidney injury are associated with hospital mortality in critically ill patients: a cohort analysis", Crit Care, 10(3), pp. 12.
3. Metnitz P. G., Krenn C. G., et al. (2002), "Effect of acute renal failure requiring renal replacement therapy on outcome in critically ill patients", Crit Care Med, 30(9), pp. 2051-8.

4. Bellomo R., Ronco C., et al. (2004), "Acute renal failure - definition, outcome measures, animal models, fluid therapy and information technology needs: the Second International Consensus Conference of the Acute Dialysis Quality Initiative (ADQI) Group", Crit Care, 8(4), pp. R204-12.

5. Đặng Thị Xuân, Hà Trân Hưng và cộng sự (2016), Nghiên cứu áp dụng phân đô RIFLEE trong đánh giá mức độ, tiến triển và tiển lượng tổn thương thân cấp ở bênh nhân hồi sức, Đại học Y HN.

6. Lê Thi Diễm Tuyểt (2010), Nghiên cứu một số đăc điểm dịch tể học, lâm sàng, cận lâm sàng và điều trị suy thận cấp trong hồi sức nội khoa, Đại hoc Y Hà Nôii.

7. Uchino S., Kellum J. A., et al. (2005), "Acute renal failure in critically ill patients: a multinational, multicenter study", JAMA, 294(7), pp. 813-8.

8. Salgado G., Landa M., et al. (2014), "Acute renal failure according to the RIFLE and AKIN criteria: a multicenter study", Med Intensiva, 38(5), pp. 271-7.

\section{ẢNH HƯởNG CỦA VÂT LIÊU LÀM MÃO RĂNG LÊN CÁC CHİ Số LÂM SÀNG NHA CHU Ở RĂNG CỔI LỚN HÀM TRÊN ĐÃ ĐIỀU TRI NộI NHA}

\section{Nguyễn Công Kiều Trang*, Đoàn Minh Trí* \\ SUMMARY \\ THE EFFECT OF DENTAL MATERIALS INFLUENCE ON PERIODENTAL PARAMETERS OF THE UPPER MAXILLARY MOLAR HAD BEEN ENDODONTIC TREATMENT AND CROWN PROSTHESIS}

\section{TÓM TẮT}

Muc tiêu: Đánh giá hiệu quả của các vât liệu chế tác mã̃o khác nhau (toàn sứ và hợp kim sứ) lển tình trang nướu tại vị trí cạnh mão. Đối tượng và phương pháp: 20bệnh nhân có nhu cầu phục hồi răng cối lớn hàm trên sau khi điều tri nội nhatai khu điều trị 3, Đại học Y Dược Thành phó Hồ Chí Minh được lựa chọn để tham gia nghiên cứu. Các đối tượng được chia thành 2 nhóm: 10 bệnh nhân ở nhóm mão toàn sứ, 10 bệnh nhân ở nhóm mão sứ kim loai.Các thông số nha chu được ghi nhận ngay sau khi gắn mão, 45 ngày sau gắn mão và 90 ngày sau khi gắn mão. Kết quả: Các thông số lâm sàng nha chu tại các thời điểm sau khi gắn phục hình, 45 và 90 ngày không có sự khác biệt có ý nghĩa thống kê giữa hai nhóm mão toàn sứ và mão sứ - kim loại. Phục hình mão răng có làm gia tăng nhe chỉ số mảng bám và chỉ số nướu ở cả hai nhóm nhưng không có sự khác biệt ýnghĩa $(p>0,05)$. Kết luận: Không có sự khác biểt về ảnh hưởng sứ và hợp kim lên chỉ sổ mô nướu quanh răng khi thực hiên phục hình mão răng.

Tư khoá: Mão toàn sứ, mão sứ kim loại, chỉ số lâm sàng nha chu.

*Đai hoc Y Dướ TP. Hồ Chí Minh

Chịu trách nhiệm chính: Nguyễn Công Kiều Trang

Email: drnguyentrang0308@gmail.com

Ngày nhận bài: 22/8/2021

Ngày phản biên khoa hoc: 30/9/2021

Ngày duyệt bài: 11/10/2021
Objective: To evaluate the effectiveness of types of dental materials (all-porcelain andporcelain -fused to metal crowns) using to make crownsinfluence on the gingival tissuesaround crowns. Material and methods: 20 patients with the upper maxillary molars had been root canal treatment at the Clinical Department 3, Faculty of Odonto Stomatology, University of Medicine and Pharmacy, Ho Chi Minh City, recruited in the study. The subjects were divided into 2 groups, included 10 -subject group was treated with all-porcelain crowns and 10 -remain group treated with porcelain-fused to metal crowns. Periodontal parameters were recorded immediately after crown cementations, 45 and 90 days subsequently. Results: The periodontal clinical parameters at the time of crown cementations, 45 and 90 days after fixed crowns showed no statistically significant differences between two groups using allporcelain crown and porcelain - fused to metal crowns. Crown prostheses caused to lightly increasing the plaque index and gingival index in both groups but there were no statistically significant differences $(p>$ 0.05). Conclusion: There were no significant differences in the effects of using all-porcelain or 